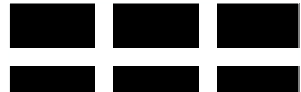 \\ THE WILLIAM DAVIDSON INSTITUTE AT THE UNIVERSITY OF MICHIGAN
}

\section{Derivatives Trading and the Volume-Volatility Link in the Indian Stock Market}

\author{
By: S. Bhaumik, M. Karanasos and A. Kartsaklas
}

William Davidson Institute Working Paper Number 935

April 2008 


\title{
Derivatives trading and the volume-volatility link in the Indian
}

\author{
stock market
}

\author{
S. Bhaumik ${ }^{\dagger}$, M. Karanasos ${ }^{\dagger}$ and A. Kartsaklas* \\ ${ }^{\dagger}$ Brunel University, West London, UK \\ *Queen Mary, University of London, UK
}

This draft: September 2008

\begin{abstract}
This paper investigates the issue of temporal ordering of the range-based volatility and volume in the Indian stock market for the period 1995-2007. We examine the dynamics of the two variables and their respective uncertainties using a bivariate dual long-memory model. We distinguish between volume traded before and after the introduction of futures and options trading. We find that in all three periods the impact of both the number of trades and the value of shares traded on volatility is negative. This result is in line with the theoretical argument that a marketplace with a larger population of liquidity providers will be less volatile than one with a smaller population. We also find that (i) the introduction of futures trading leads to a decrease in spot volatility, (ii) volume decreases after the introduction of option contracts and, (iii) there are significant expiration day effects on both the value of shares traded and volatility series.
\end{abstract}

Keywords: derivatives trading; emerging markets; long-memory; range-based volatility; value of shares traded

\section{Introduction}

With the rapid growth in the market for financial derivatives, and assuming that they are responsible for more volatile financial markets, perhaps even responsible for the financial crash of 1987, research since the 
crash has explored their impact on volatility in the spot equity (or cash) market. The effect of derivatives trading on cash market volatility is theoretically ambiguous and depends on the specific assumptions of the model (see Mayhew 2000). In keeping with this, the empirical evidence is also mixed. While some researchers have found that the introduction of futures and options trading has not had any impact on stock volatility, others have found evidence of a positive effect in a number of countries including, Japan, the UK and the USA. The balance of evidence suggests that introduction of derivatives trading may have increased volatility in the cash market in Japan and the USA, but it had no impact on the other markets (Gulen and Mayhew, 2000).

Even as the sophistication of financial markets improve around the world, and trading in financial derivatives spreads across emerging markets, the aforementioned literature is almost entirely restricted to developed country contexts. It is only recently that the development and financial literature have started exploring the impact of phenomena like market participation by foreign portfolio investors and expiration of derivatives contracts in emerging economies (see, for example, Vipul, 2005; Kim et al., 2005; Karanasos and Kartsaklas, 2008a; Wang, 2007). Few of these papers examine the effect of the introduction of financial derivatives on cash market volatility (and none of them explores their effects on the volume-volatility relationship), even though the market risk associated with such volatility is likely to have a greater economic influence on market participation by investors (and hence cost of capital) in emerging markets than in developed financial markets.

We address the lacuna in the literature about the impact of derivatives trading on the volatility of cash markets in emerging market economies by examining how the introduction of futures and options affected the volume-volatility link at the National Stock Exchange (NSE), the largest stock exchange in India. Using both daily and intra-day data from the NSE, we first analyze the volatility and volume dynamics in the cash market. We estimate the two main parameters driving the degree of persistence in the two variables and their respective uncertainties using a bivariate constant conditional correlation (ccc) Generalized ARCH (GARCH) model that is Fractionally Integrated (FI) in both the Autoregressive (AR) and variance specifications. We refer to this model as the AR-FI-GARCH. It provides a general and flexible framework with which to study complicated processes like volume and volatility. Put differently, 
it is sufficiently flexible to handle the dual long-memory behavior encountered in the two series.

Next we attempt to shed more light on the issue of temporal ordering of volume and volatility. To do this we estimate the bivariate ccc AR-FI-GARCH model with lagged values of one variable included in the mean equation of the other variable. The empirical evidence on this link remains scant or nonexistent, as pertains, in particular, to Indian data after the introduction of derivatives trading. The most commonly used measures of volatility are the absolute values of the returns, their squares and conditional variances from a GARCH-type of model (see Kim et al., 2005). In this study we employ the classic range-based estimator of Garman and Klass (1980) (hereafter GK). The GK estimator is more efficient than the traditional close-to-close estimator and exhibits very little bias, whereas the realized volatility constructed from high frequency data can possess inherent biases impounded by market microstructure factors (see Karanasos and Kartsaklas, 2008a and the references therein). We also use number of trades and value of shares traded as two alternative measures of volume. As pointed out by Kawaller et al. (2001), empirical evidence of an inverse relation between the two variables is rare in the literature, and the widely held perception is that the two are positively related. However, evidence about a negative relationship between volume and volatility is not absent altogether. Daigler and Wiley (1999) find that the activity of informed traders is often inversely related to volatility. Wang (2007) argues that foreign purchases tend to lower volatility, especially in the first few years after market liberalization when foreigners are buying into local markets. Karanasos and Kartsaklas (2008a) show that, in Korea, the causal negative impact from total volume to volatility reflects the causal relation between foreign volume and volatility. Therefore, we investigate the significance and the sign of the causal effect.

Our sample period from November 3, 1995 to January 25, 2007 includes the introduction of (index) futures and (index) options trading. We feel that it is sensible to distinguish volume traded before and after the introduction of each of these financial instruments. In other words, we have three distinct subperiods in our data. The results suggest that the effects from the value of shares traded on volatility are sensitive to the introduction of derivatives trading. In all three periods the effect is negative. However, in the period from the introduction of options contracts until the end of the sample its impact on volatility, although still significantly negative, is much smaller in size. Hence, the advent of options trading may 
have weakened the impact volume has on volatility through the information route. Similarly, the impact of the number of trades on volatility is negative in all three periods. This observation is consistent with the view that a marketplace with a larger population of liquidity providers will be less volatile than one with a smaller population. In sharp contrast, both measures of volume are independent from changes in volatility.

We also find that (i) the introduction of futures trading leads to a decrease in spot volatility as predicted by Stein (1987) and Hong (2000) and, (ii) volume decreases after the introduction of option contracts, offering support to the view that the migration of some speculators to options markets on the listing of options is accompanied by a decrease in trading volume in the underlying security. We also use both stylised non-parametric tests and the bivariate ccc AR-FI-GARCH model to analyse the impact of expiration of derivatives contracts on the cash market at the NSE. Our results indicate that expiration of equity based derivatives has a significant positive impact on the value of shares traded on expiration days and a negative one on the range-based volatility. The increased trading on expiration days can easily be explained by way of settlement of futures contracts (and exercise of options contracts) that necessitate purchase and sale of shares in the cash market. The evidence of reduction in range-based volatility is consistent with that of Vipul (2006), who argues that this reduction is attributable to a decrease in the persistence of range-based volatility from one trading day to the next.

The remainder of this article is organised as follows. In Section 2, we trace the post-reforms evolution of the secondary market for equities in India. Section 3 discusses the theory concerning the link between volume and volatility and the impact of futures trading on the latter. Section 4 outlines the data which are used in the empirical tests of this paper. In Section 5 we describe the time series model for the two variables and we report the empirical results. Section 6 discusses our results within the context of the Indian market. Section 7 contains summary remarks and conclusions.

\section{The Indian Equity Market}

The reform of India's capital market was initiated in 1994, with the establishment of the NSE, which pioneered nationwide electronic trading at its inception, a neutral counterparty for all trades in the form 
of a clearing corporation and paperless settlement of trades at the depository (in 1996). The consequence was greater transparency, lower settlement costs and fraud mitigation, and one-way transactions costs declined by $90 \%$ from an estimated $5 \%$ to $0.5 \%$.

However, important structural problems persisted. Perhaps the most important of these problems was the existence of leveraged futures-type trading within the spot or cash market. This was facilitated by the existence of trading cycles and, correspondingly, the absence of rolling settlement. Given a WednesdayTuesday trading cycle, for example, a trader could take a position on a stock at the beginning of the cycle, reverse her position towards the end of the cycle, and net out her position during the long-drawn settlement period. In addition, the market allowed traders to carry forward trades into following trading cycles, with financiers holding the stocks in their own names until the trader was able to pay for the securities and the intermediation cost, which was linked to money market interest rates (for details, see Gupta, 1995, 1997). The Securities and Exchange Board of India (SEBI) banned the use of carry forward (or badla) trades in March 1994, following a major stock market crash. However, in response to worries about decline in market liquidity and stock prices, stemming from the crash in the price of stocks of MS Shoes, carry forward was reintroduced in July 1995.

However, the crisis of 1994 had initiated a policy debate that resulted in significant structural changes in the Indian equity market by the turn of the century. On January 10, 2000, rolling settlement was introduced for the first time, initially for ten stocks. By July 2, 2001, rolling settlement had expanded to include 200 stocks, and badla or carry forward trading was banned. In the interim, in June 2000, the NSE (as well as its main rival, the Bombay Stock Exchange) introduced trading in stock index futures, based on its 50-stock market capitalisation weighted index, the Nifty (and, correspondingly, the 30-stock Sensex). Index options on the Nifty and individual stocks were introduced in 2001, on June 4 and July 2, respectively. Finally, on November 9, 2001, trading was initiated in futures contracts based on the prices of 41 NSE-listed companies. However, in a blow to the price discovery process in the cash market, prior to the introduction of derivatives trading in India, the SEBI banned short sales of stocks listed on the exchanges.

Some details about the derivatives contracts are presented next. Contracts of three different durations, 
expiring in one, two and three months, respectively, are traded simultaneously. On each trading day, they are traded simultaneously with the underlying stocks, between 8.55 am and $3.30 \mathrm{pm}$. The closing price for a trading day is the weighted-average of prices during the last hour and a half of the day, and this price is the basis for the settlement of these contracts. The futures and options contracts on the indices as well as those on individual stocks expire on the last Thursday of every month, resulting in a quadruple witching hour.

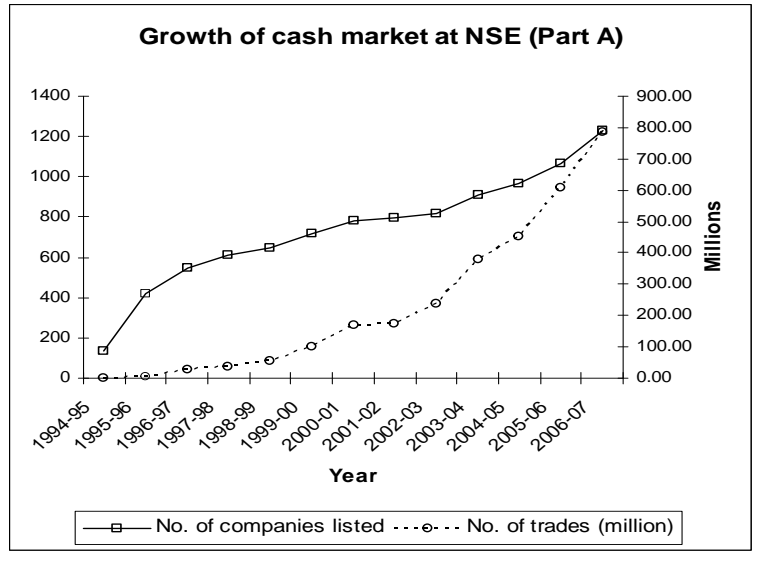

Figure 1 (Part A)

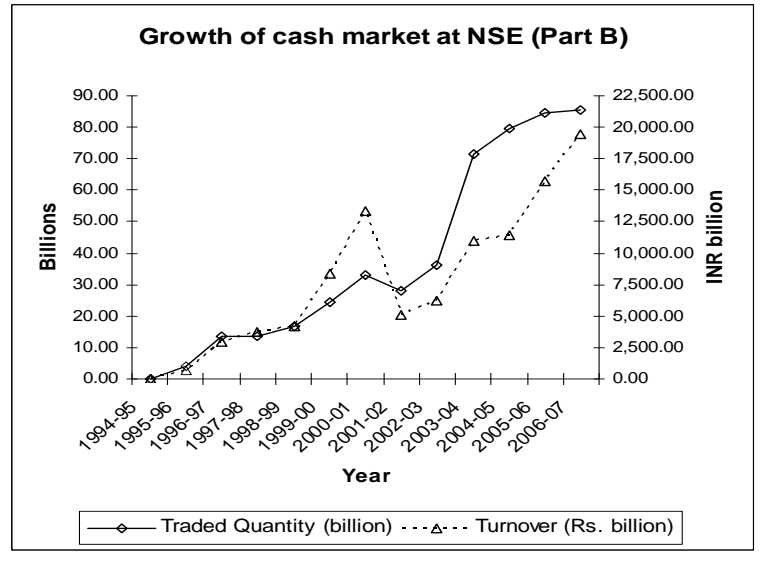

Figure 1 (Part B)

The choice of NSE as the basis for our analysis can easily be justified. The market capitalisation in March 2007, the last month of the 2006-07 financial year, was Indian rupees (INR) 33,673.5 billion, more than 10 times the market capitalisation in March 1995 (INR 2,926.4 billion), the last month of NSE's first (financial) year of operation. The number of trades executed at NSE's cash market during the corresponding months was 71 million and 0.1 million, respectively. The growth in the derivatives segment of the exchange has kept pace with the growth in the cash market. Of the 1098 listed securities, 123 act as underlying assets for futures and options contracts. In addition, three indices are used as the underlying assets for futures and options trading at the exchange. The turnover in the derivatives segment increased from INR 3.81 billion in March 2001, the last month of the first (financial) year of derivatives trading at NSE, to INR 6,937.63 billion in March 2007. The corresponding increase in the daily average turnover was from INR 0.18 billion to INR 330.36 billion. In March 2007, the daily turnover in the derivatives 
segment of the equity market was $413 \%$ of the average daily turnover in the cash segment of the market.

The meteoric growth of the cash and derivatives segments of the NSE is graphically highlighted in Figures $1-2$.

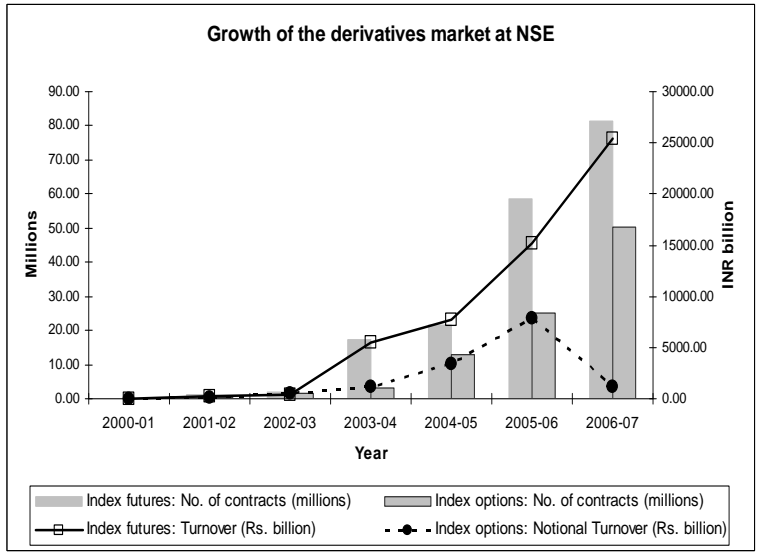

Figure 2

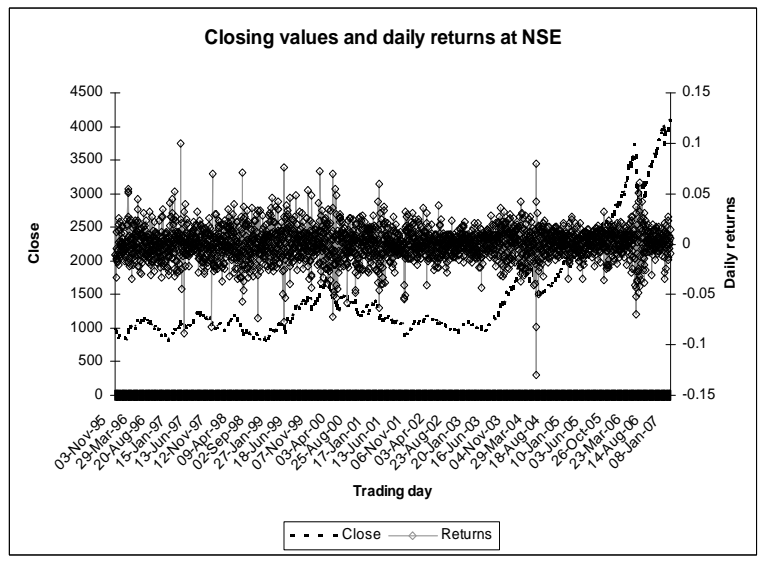

Figure 3

\section{Theoretical Background}

\subsection{Economic rationale for a negative volume-volatility link}

Several theoretical models try to explain the volatility-volume relation either by describing the full process by which information integrates into prices or by using a less structural approach such as the Mixture of Distribution Hypothesis (MDH). According to various MDH models there is a positive relation between current stock return variance and trading volume (see Kim et al., 2005, and the references therein). Andersen (1996) suggests a modified MDH model in which returns $\left(r_{t}\right)$ are decomposed to information and non-information components and volume to informed $\left(V_{t}^{(I)}\right)$ and liquidity $\left(V_{t}^{(L)}\right)$ components. In Andersen's framework $\operatorname{Cov}\left(r_{t}^{2}, V_{t}^{(L)}\right)=0$. As pointed out by Kawaller et al. (2001), empirical evidence of an inverse relation between the two variables is rare in the literature, and it contrasts sharply with the widely held perception that the two are positively correlated (see also Karanasos and Kartsaklas, 2008a). Moreover, Daigler and Wiley (1999) find empirical evidence indicating that the positive volume-volatility relation is driven by the (uninformed) general public whereas the activity of informed traders such as 
clearing members and floor traders is often inversely related to volatility.

In addition, the activity of market makers (liquidity providers) occurs independently of information arrival. Kawaller et al. (2001) argue that an increase in such noninformation-based trading mitigates the imbalances between liquidity suppliers and liquidity demanders by enhancing the market's capacity to absorb the information-induced trading. Accordingly, all else being equal, a marketplace with a larger population of liquidity providers (or a larger capacity to absorb demands for liquidity) will be less volatile than one with a smaller population, and vice versa (Kawaller et al., 2001). Li and Wu (2006) employ the Easley et al. (1996) set up that includes informed and uninformed traders and a risk-neutral competitive market maker. They show that in this sequential trade model the higher the intensity of liquidity trading, the lower the price volatility. They also highlight the fact that this negative relationship exists in any variant of the Bayesian learning model (see, for example, Easley et al., 2002). In their empirical investigation they find that $\operatorname{Cov}\left(r_{t}^{2}, V_{t}^{(L)}\right)$ is significantly negative.

Furthermore, in a market with partially informed investors, broadening the investor base increases risk sharing and stock prices. A simple extension of this analysis shows that broadening the investor base improves the accuracy of market information and stabilises stock prices (see Wang, 2007 and the references therein). Therefore foreign purchases tend to lower volatility by increasing the investor base in emerging markets. This is especially the case in the first few years after market liberalization when foreigners are buying into local markets, and is consistent with findings of stable stock markets after liberalization. In sharp contrast, foreign sales reduce investor base and increase volatility. Karanasos and Kartsaklas (2008a) find that, in Korea, the negative causal effect from total volume to volatility reflects the causal relation between foreign volume and volatility before the financial crisis.

\subsection{The impact of futures trading on spot market volatility}

The impact of the opening of futures markets on the spot price volatility has received considerable attention in the finance literature. Researchers and practitioners have investigated the role that the introduction of futures trading played in the stock market crash of 1987 in the USA (Gammill and Marsh, 1988) and in the Asian financial crisis (Ghysels and Seon, 2005).

Several researchers have studied the level of the spot stock volatility before and after the introduction 
of futures contracts. Theoretical studies on the impact of the futures trading on the spot volatility have produced ambiguous results. Stein (1987) demonstrates the fact that opening a futures market is exactly equivalent to allowing more speculators to participate in the spot market. He focuses on two aspects of speculative behavior, risk sharing and information transmission. Stein argues that when the addition of speculators just raises the number of perfectly informed participants in the market and, hence, has no informational effect at all, then the opening of a futures market is stabilizing and welfare improving. In other words, in this case we are left with only the beneficial effect of pure risk sharing. Even when secondary traders have no private information and must rely solely on market prices to make their judgments, increases in the number of uniformed traders are stabilizing if these traders do not inflict any negative informational externality on the informed traders. However, if there is a muddling of the spot traders information then destabilizing speculation occurs.

A number of researchers propose theoretical models where the introduction of futures trading destabilize prices in the spot market (see Board et al., 2001 and the references therein). Subrahmanyan (1991) presents a theory of trading in markets for stock index futures or, more generally, for baskets of securities. His model incorporates trading by two types of strategic liquidity traders: discretionary and non-discretionary. Although it has been suggested that the opening of a futures market may destabilize prices by encouraging noise trading. Subrahmanyan argues that this need not necessarily be a cause for concern. In his model an increase in noise trading actually makes price more informative by increasing the returns on being informed and thereby facilitating the entry of more informed traders. He states (see proposition 9 in his paper) that if the number of informed traders is not constant over time, the effect of the introduction of a basket on individual security price variability is ambiguous. Hong (2000) develops an equilibrium model of competitive futures markets in which investors trade to hedge positions and to speculate on their private information. He finds that when a futures market is opened investors are able to better hedge spot price risk and hence are more willing to take on larger spot positions. As a result the introduction of futures contracts reduces spot price volatility.

As far as the empirical evidence is concerned Damodaran and Subrahmanayan (1992) survey a number of studies. They conclude that there is a consensus that listing futures on commodities reduces the 
variances of the latter. Edwards (1988) and Bessembinder and Seguin (1992) find that S\&P 500 futures trading affects spot volatility negatively. Brown-Hruska and Kuserk (1995) also provide evidence, for the S\&P 500 index, that an increase in futures volume (relative to spot volume) reduces spot volatility. Dennis and Sim (1999) document how the introduction of futures trading does not affect spot market volatility significantly in Australia and three other nations. Gulen and Mayhew (2000) find that spot volatility is independent of changes in futures trading in eighteen countries and that informationless futures volume has a negative impact on spot volatility in Austria and the UK. The analysis in Board et al. (2001) suggests that in the UK futures trading does not destabilize the spot market. In general, mixed evidence is provided by studies that examine non-US markets. For example, Bae et al. (2004) find that the introduction of futures contracts in Korea is associated with greater spot price volatility. Overall, the impact of futures trading on the volatility of spot markets varies according to sample, data set and methodology chosen.

The impact of derivatives trading on the volatility of the cash market in India is explored in a few studies (Bandivadekar and Ghosh, 2003; Raju and Karande, 2003; Vipul, 2006). The empirical evidence suggests that as early as 2002-03 there was a reduction in the volatility of the cash market index after the introduction of index futures. Vipul (2006) find evidence of a reduction in the volatility of the prices of underlying securities after the introduction of futures contracts for individual stocks. However, these papers do not explore the volume-volatility link, nor separately the impact of futures and options trading on the underlying market. In what follows we will examine, within the context of a bivariate long-memory model, the effect of the opening of futures markets on spot price volatility and volume at the NSE.

\section{Data and Estimation Procedure}

The data set used in this study comprises 2814 daily trading volumes and prices of the NSE index, running from 3rd of November 1995 to 25th of January 2007. The data were obtained from the Indian NSE. The NSE index is a market value weighted index for the 50 most liquid stocks. 


\subsection{Price volatility}

Using data on the daily high, low, opening, and closing prices in the index we generate a daily measure of price volatility. We can choose from among several alternative measures, each of which uses different information from the available daily price data. To avoid the microstructure biases introduced by high frequency data, and based on the conclusion of Chen et al. (2006) that the range-based and high-frequency integrated volatility provide essentially equivalent results, we employ the classic range-based estimator of Garman and Klass (1980) to construct the daily volatility $\left(y_{t}^{(g)}\right)$ as follows

$$
y_{t}^{(g)}=\frac{1}{2} u^{2}-(2 \ln 2-1) c^{2}, \quad t \in \mathbb{N},
$$

where $u$ and $c$ are the differences in the natural logarithms of the high and low, and of the closing (at time $t$ ) and opening (at time $t-1$ ) prices respectively. Figure 4A plots the GK volatility from 1995 to 2007.

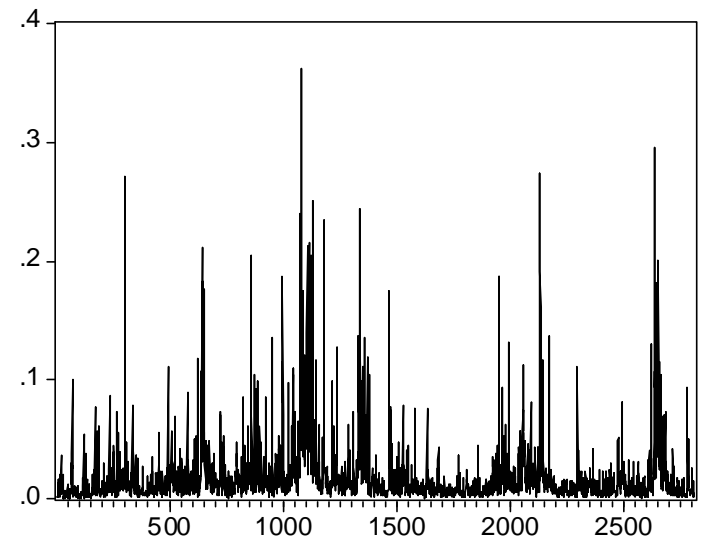

Figure 4A (Garman-Klass Volatility)

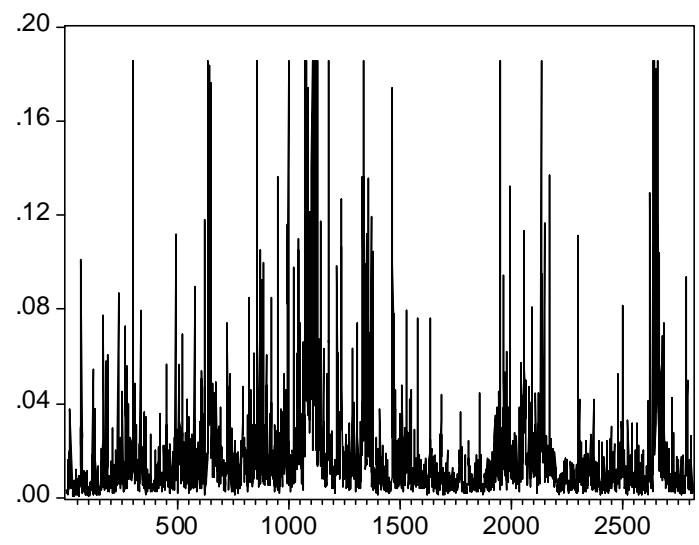

Figure 4B (Outlier reduced GK volatility)

Various measures of GK volatility have been employed by, among others, Daigler and Wiley (1999), Kawaller et al. (2001), Wang (2002), Chen and Daigler (2004) and Chen et al. (2006) (see Karanasos 
and Kartsaklas, 2008a, and the references therein). ${ }^{1}$

We also use an outlier reduced series for Garman-Klass volatility (see Figure 4B). In particular, the variance of the raw data is estimated, and any value outside four standard deviations is replaced by four standard deviations. Chebyshev's inequality is used as it i) gives a bound of what percentage $\left(1 / k^{2}\right)$ of the data falls outside of $k$ standard deviations from the mean, ii) holds no assumption about the distribution of the data, and iii) provides a good description of the closeness to the mean,especially when the data are known to be unimodal as in our case. ${ }^{2}$

\subsection{Trading activity}

We use the value of shares traded and the number of trades as two alternative measures of volume. Because trading volume is nonstationary several detrending procedures for the volume data have been considered in the empirical finance literature (see, for details, Karanasos and Kartsaklas, 2008a). We form a trend-stationary time series of volume $\left(y_{t}^{(v)}\right)$ by fitting a linear trend $(t)$ and subtracting the fitted values for the original series $\left(\widetilde{y}_{t}^{(v)}\right)$ as follows

$$
y_{t}^{(v)}=\widetilde{y}_{t}^{(v)}-(\hat{a}-\hat{b} t)
$$

where $v$ denotes volume. The linear detrending procedure is deemed to provide a reasonable compromise between computational ease and effectiveness. We also extract a moving average trend from the volume series. As detailed below, the results (not reported) for the moving average detrending procedure are almost identical to those reported for the linearly detrended volume series. ${ }^{3}$

In what follows, we will denote value of shares traded by $v s$ and number of trades by $n$. Figures $5 \mathrm{~A}$ and 5B and plot the number of trades and value of shares traded from November 1995 to January 2007.

\footnotetext{
${ }^{1}$ Chou (2005) propose a Conditional Autoregressive Range (CARR) model for the range (defined as the difference between the high and low prices). In order to be in line with previous research (Daigler and Wiley, 1999, Kawaller et al., 2001, and Wang, 2007) in what follows we model GK volatility as an autoregressive type of process taking into account bidirectional feedback between volume and volatility, dual-long memory characteristics and GARCH effects.

${ }^{2}$ Carnero et al. (2007) investigate the effects of outliers on the estimation of the underlying volatility when they are not taken into account.

${ }^{3}$ Bollerslev and Jubinski (1999) find that neither the detrending method nor the actual process of detrending affected any of their qualitative findings (see also, Karanasos and Kartsaklas, 2008a and the references therein).
} 


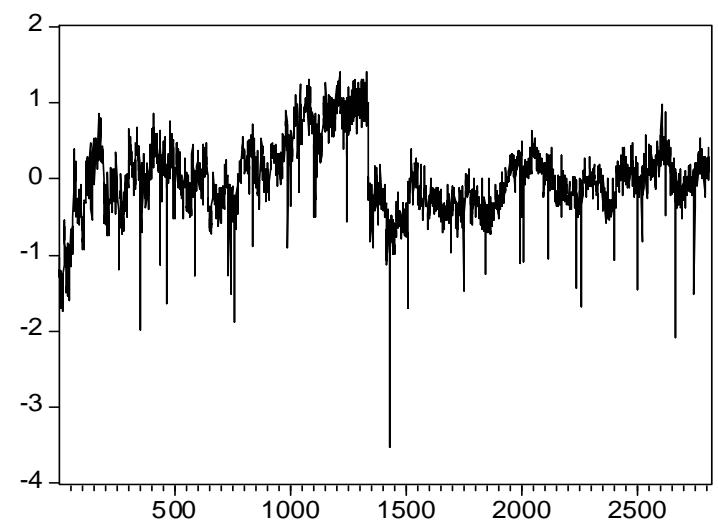

Figure 5A (Value of shares traded)

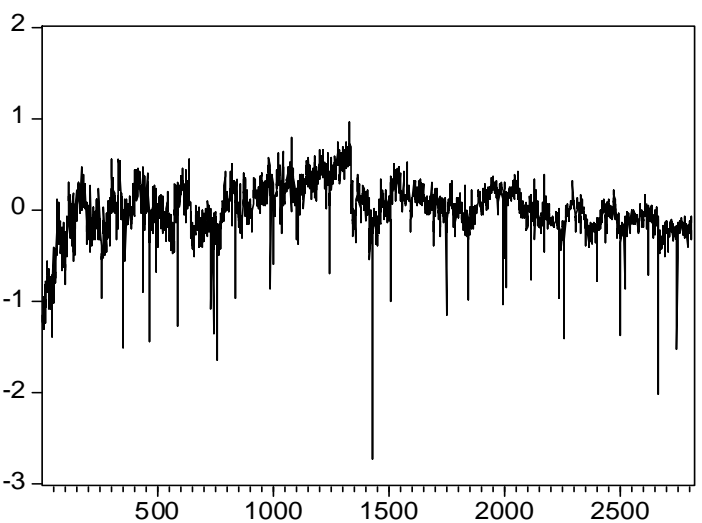

Figure 5B (Number of trades)

\subsection{Breaks and the introduction of financial derivatives}

We also examine whether there are any structural breaks in both volume and volatility and, if there are, whether they are associated with the introduction of futures and options contracts. We test for structural breaks by employing the methodology in Bai and Perron (2003), who address the problem of testing for multiple structural changes in a least squares context and under very general conditions on the data and the errors. In addition to testing for the presence of breaks, these statistics identify the number and location of multiple breaks. In this study in the case of log volume we use a partial structural change model where we test for a structural break in the mean while at same time allowing for a linear trend of the form $t / T$.

Moreover, Bai and Perron (2003) form confidence intervals for the break dates under various hypotheses about the structure of the data and the errors across segments. This allows us to estimate models for different break dates within the 95 percent confidence interval and also evaluate whether our inferences are robust to these alternative break dates. Our results (not reported) seem to be invariant to break dates around the one which minimizes the sum of squared residuals.

The overall picture dates two change points for volatility. The first is detected on the 27th of July 2000 ( recall that the index futures trading started on 12 June 2000) and the next one is on 12th of May 2006. As regards trading volume, both series, value of shares traded and number of trades, have a 
common break dated on the 7th of March 2001. This is almost three months before the introduction of options contracts. Accordingly, we break our entire sample into three sub-periods. 1st period (the period up to the introduction of futures trading): 3rd November 1995 - 12th June 2000; 2nd: 13th June 2000 - 2nd July 2001 that is, the period from the introduction of futures contracts until the introduction of options trading; the 3rd period is the one which starts with the introduction of option contracts: 3rd July 2001 - 25th January 2007.

Lavielle and Moulines (2000) extended the results of Bai and Perron (1998) and show that an appropriately modified version of the Schwarz criterion yields a consistent estimator of the number of change points under very weak conditions on the structure of the disturbances. Particularly, their results are valid under a wide class of strongly dependent processes, including long memory, GARCH-type and nonlinear models. Lavielle and Moulines's penalised least squares estimator is also used to identify whether the number of break points is consistently estimated as it is evident that trading volume and volatility exhibit long memory characteristics. Our results show that there is no change in the number of break points estimated when we allow for strongly dependent process or long memory.

\subsection{Expiration effects}

By its very nature, arbitrage between the cash and (especially) futures markets requires investors to unwind positions in the latter market on the day of expiration of contracts, in order to realize arbitrage profits. The consequent increase in the number of large buy and sell orders, and the temporary mismatch between these orders, can significantly affect prices and volatility in the underlying cash market. Not surprisingly, regulators around the world have responded with a number of measures aimed at reducing price volatility on account of the so-called expiration effect of index derivatives.

The importance of expiration day effects on the cash market to regulators has, in turn, generated interest in such effects within the research community. As a consequence, the impact of expiration of futures and options contracts on the underlying cash market has been examined in a number of contexts (see, e.g., Stoll and Whaley, 1997, Bollen and Whaley, 1999, Corredor et al., 2001, Chow et al., 2003, and Alkeback and Hagelin, 2004). The empirical evidence is not unequivocal, and the nature of the influence of expiration of derivatives on underlying cash prices remains an open question (see, Bhaumik and Bose, 
2008, and the references therein).

We first examine the impact of the expiration of the derivatives contracts on the volumes of trade in the spot market at the NSE. The total number of trades executed in the cash segment of the exchange, and the ratio of the trades concluded on expiration (Thurs)days to the trades concluded on a control category of non-expiration days are highlighted in Figure 6A. The control category is the average of concluded trades on Thursdays one and two weeks prior to the expiration Thursday. Three things are evident from the figure: First, the numbers of trades on expiration days and the control category are closely correlated; the correlation coefficient is 0.91. Second, as noted earlier in the paper, there was a significant increase in the number of trades executed in the cash segment of the market over time. Not surprisingly, therefore, the ratio of number of trades on the expiration day to the number of trades included in the control category average $(r)$ is close to unity, namely, 1.07. However, the null hypothesis that $r=1$ is rejected at the 1 percent level, the alternative hypothesis being $r>1$. In other words, in the cash market, the number of trades on the expiration day, on average, significantly exceeds the average number of trades on the Thursdays of the previous two weeks of trading.

Comparative trading: Expiration day vs. control

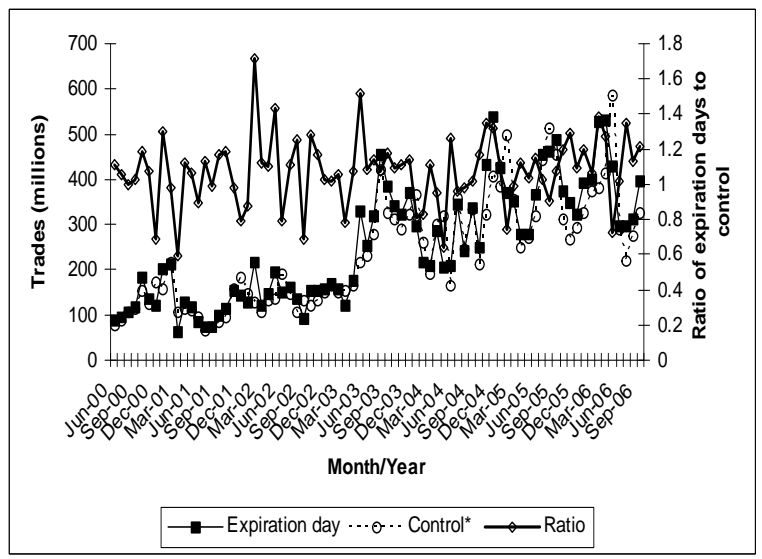

Figure 6A (Number of Trades)

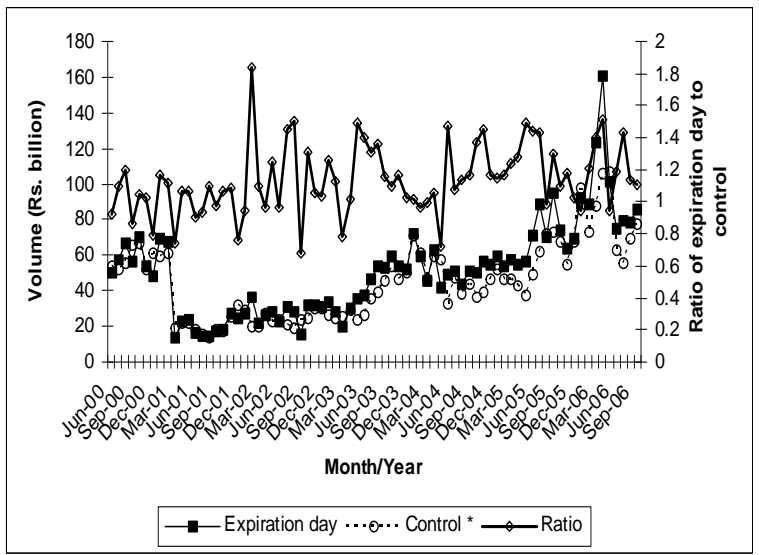

Figure 6B (Volume of Trade)

Note: * Average of reported volume on Thursdays 1 and 2 weeks prior to expiration Thursday.

Figure $6 \mathrm{~B}$ reports the impact of expiration of derivatives contracts on the volume of trade that is 
measured in INR billion. It is evident that the patterns and trends reported in Panel B are very similar to those reported in Panel A. As in the case of number of trades, the volume of trade increases significantly over time, and the volume of trade on expiration days is highly correlated (0.92) with the volume of trade on the control days. The ratio of the volume of trade on expiration days to the volume of trade on control days has an average of 1.13 , and the null hypothesis that this ratio equals 1 is rejected at the 1 percent level, when the alternative hypothesis is that the ratio exceeds 1 .

Next, we test the impact of the expiration of derivatives contracts on range-based GK volatility. The null hypothesis for each test is that the mean (median) value of volatility during expiration Thursdays equals the mean (median) of volatility on non-expiration Thursdays. In addition to the stylized t-test for the equality of means, and the Wilcoxon rank-sum test for the equality of medians, we use the the Kruskal-Wallis test (for other uses of the test, see Megginson and Weiss, 1991). Our test statistics, reported in Table 1, suggest that expiration of derivatives contracts does not have an impact on rangebased volatility on the day of expiration of derivatives contracts. This is true both for the entire postJune 2000 period, and for the post- February 2002 period during which foreign investors were allowed to invest in equity derivatives in the Indian capital market.

Table 1. Impact of derivatives trading on range-based volatility

\begin{tabular}{lllllll}
\hline & t-test & & \multicolumn{2}{c}{ Wilcoxon rank-sum test } & \multicolumn{2}{c}{ Kruskal-Wallis test } \\
\hline & t-statistic & p-value & z-statistic & p-value & Chi Square & p-value \\
June 2000 - January 2007 & 0.67 & 0.50 & 0.39 & 0.69 & 0.15 & 0.69 \\
February 2002 - January 2007* & 0.27 & 0.78 & 0.39 & 0.69 & 0.001 & 0.98 \\
\hline
\end{tabular}

Note: ${ }^{*}$ Foreign institutional investors were allowed to invest in equity derivative products from February 2002

\section{Model and Empirical Results}

\subsection{Bivariate long-memory process}

Tsay and Chung (2000) have shown that regressions involving FI regressors can lead to spurious results. Moreover, in the presence of conditional heteroskedasticity Vilasuso (2001) suggests that causality tests be carried out in the context of an empirical specification that models both the conditional means and 
conditional variances.

Furthermore, in many applications the sum of the estimated variance parameters is often close to one, which implies integrated GARCH (IGARCH) behavior. For example, Chen and Daigler (2004) emphasize that in most cases both variables possess substantial persistence in their conditional variances. In particular, the sum of the variance parameters was at least 0.950. Most importantly, Baillie et al. (1996), using Monte Carlo simulations, show that data generated from a process exhibiting FIGARCH effects may be easily mistaken for IGARCH behavior. Therefore we focus our attention on the topic of long-memory and persistence in terms of the second moments of the two variables. Consequently, we utilize a bivariate ccc AR-FI-GARCH model to test for causality between volume and volatility.

Within the framework of the bivariate ccc AR-FI-GARCH model we will analyze the dynamic adjustments of both the conditional means and variances of volume and volatility, as well as the implications of these dynamics for the direction of causality between the two variables. The estimates of the various formulations were obtained by quasi maximum likelihood estimation (QMLE) as implemented by James Davidson (2008) in Time Series Modelling (TSM). To check for the robustness of our estimates we used a range of starting values and hence ensured that the estimation procedure converged to a global maximum.

Next let us define the column vector of the two variables $\mathbf{y}_{t}$ as $\mathbf{y}_{t}=\left(y_{t}^{(g)} y_{t}^{(v)}\right)^{\prime}$ and the residual vector $\varepsilon_{t}$ as $\varepsilon_{t}=\left(\varepsilon_{t}^{(g)} \varepsilon_{t}^{(v)}\right)^{\prime}$. In order to make our analysis easier to understand we will introduce the following notation. $D_{t}^{(f)}$ is a dummy defined as: $D_{t}^{(f)}=1$ during the period from the introduction of futures trading (that is 13th June 2000) until the end of the sample and $D_{t}^{(f)}=0$ otherwise; similarly $D_{t}^{(o)}$ is a dummy indicating approximately the period which starts with the introduction of option contracts. That is, $D_{t}^{(o)}=1$ in the period between 3rd July 2001 and 25th January 2007 and $D_{t}^{(o)}=0$ otherwise. In addition, $D_{t}^{(e)}$ is a dummy defined as: $D_{t}^{(e)}=1$ the last Thursday of every month -starting from the introduction of futures trading- and $D_{t}^{(e)}=0$ otherwise.

In the expression below the superscripts $g$ and $v$ mean that the first equation represents the volatility and the second one stands for the volume. When the value of shares traded is used as a measure of volume, that is when $v=v s$, we will refer to the above expression as model 1. Similarly, when we use

\footnotetext{
${ }^{4}$ Karanasos and Kartsaklas (2008a) applied the bivariate dual long-memory process to model the volume-volatility link in Korea.
} 
the number of trades, that is when $v=n$, we will have model 2 .

The best fitting specification (see equation 1 below) is chosen according to the minimum value of the information criteria (not reported). For the conditional mean of volatility $(g)$, we choose an $\operatorname{ARFI}(0)$ process for both measures of volume. For the conditional means of value of shares traded $(v s)$ and number of trades $(n)$, we choose an $\operatorname{ARFI}(10)$ process. That is, $\Phi^{(v)}(L)=1-\sum_{k=1}^{10} \phi_{k}^{(v)} L^{k}, v=v s, n$, with $\phi_{4}^{(v s)}=\phi_{6}^{(v s)}=\phi_{7}^{(v s)}=\phi_{9}^{(v s)}=0$, for the value of shares traded, and only $\phi_{4}^{(n)} \neq \phi_{5}^{(n)} \neq \phi_{9}^{(n)} \neq \phi_{10}^{(n)} \neq 0$ for the number of trades. We do not report the estimated AR coefficients for space considerations.

The chosen estimated bivariate ARFI model is given by

$$
\begin{aligned}
& {\left[\begin{array}{cc}
(1-L)^{d_{m}^{(g)}} & 0 \\
0 & (1-L)_{m}^{d_{m}^{(v)}} \Phi^{(v)}(L)
\end{array}\right] \times} \\
& \left\{\left[\begin{array}{c}
y_{t}^{(g)} \\
y_{t}^{(v)}
\end{array}\right]-\left[\begin{array}{c}
\phi_{3}^{(g v)} L^{3} y_{t}^{(v)}+\phi_{3}^{(g v, f)} L^{3} D_{t}^{(f)} y_{t}^{(v)}+\phi_{3}^{(g v, o)} L^{3} D_{t}^{(o)} y_{t}^{(v)} \\
\phi_{1}^{(v g)} L y_{t}^{(g)}+\phi_{1}^{(v g, f)} L D_{t}^{(f, o)} y_{t}^{(g)}+\phi_{1}^{(v g, o)} L D_{t}^{(o)} y_{t}^{(g)}
\end{array}\right]\right. \\
& \left.-\left[\begin{array}{c}
\mu^{(g)}+\mu^{(g, e)} D_{t}^{(e)}+\mu^{(g, f)} D_{t}^{(f)}+\mu^{(g, o)} D_{t}^{(o)} \\
\mu^{(v)}+\mu^{(v, e)} D_{t}^{(e)}+\mu^{(v, f)} D_{t}^{(f)}+\mu^{(v, o)} D_{t}^{(o)}
\end{array}\right]\right\}=\left[\begin{array}{c}
\varepsilon_{t}^{(g)} \\
\varepsilon_{t}^{(v)}
\end{array}\right],
\end{aligned}
$$

where $L$ is the lag operator, $0<d_{m}^{(i)}<1$ and $\mu^{(i)}, \mu^{(i, e)}, \mu^{(i, f)}, \mu^{(i, o)} \in(0, \infty)$ for $i=g, v$.

The $\phi_{s}^{(g v)}$ coefficient captures the effect from volume on volatility while $\phi_{s}^{(v g)}$ represents the impact on the opposite direction. The information criteria (not reported) choose the model with the third lag of $\phi_{s}^{(g v)}$ and the first lag of $\phi_{s}^{(v g)}$. Similarly, $\phi_{3}^{(g v, f)}, \phi_{1}^{(v g, f)}$ correspond to the cross effects from the introduction of futures contracts onwards while $\phi_{3}^{(g v, o)}, \phi_{1}^{(v g, o)}$ stand for the volume-volatility feedback after the introduction of options trading. Thus, the link between the two variables is captured by $\phi_{3}^{(g v)}$, $\phi_{1}^{(v g)}$, in the period up to the introduction of futures trading, by $\phi_{3}^{(g v)}+\phi_{3}^{(g v, f)}, \phi_{1}^{(v g)}+\phi_{1}^{(v g, f)}$ in the second period, and by $\phi_{3}^{(g v)}+\phi_{3}^{(g v, f)}+\phi_{3}^{(g v, o)}, \phi_{1}^{(v g)}+\phi_{1}^{(v g, f)}+\phi_{1}^{(v g, o)}$ in the period which starts with the introduction of options contracts. The coefficients $\mu^{(g, e)}, \mu^{(v, e)}$ capture the impact of the expiration of derivatives contracts on the two variables. 
We assume $\varepsilon_{t}$ is conditionally normal with mean vector $\mathbf{0}$, variance vector $\mathbf{h}_{t}=\left(h_{t}^{(g)} h_{t}^{(v)}\right)^{\prime}$ and $\operatorname{ccc} \rho=h_{t}^{(g v)} / \sqrt{h_{t}^{(g)} h_{t}^{(v)}}(-1 \leq \rho \leq 1)$. We also choose an $\operatorname{ARCH}(1)$ process for the volume and a $\operatorname{FIGARCH}(0, d, 0)$ one for the volatility:

$$
\left[\begin{array}{c}
h_{t}^{(g)}-\omega^{(g)} \\
h_{t}^{(v)}-\omega^{(v)}
\end{array}\right]=\left[\begin{array}{cc}
1-(1-L)^{d_{v}^{(g)}} & 0 \\
0 & \alpha^{(v)} L
\end{array}\right]\left[\begin{array}{c}
{\left[\varepsilon_{t}^{(g)}\right]^{2}} \\
{\left[\varepsilon_{t}^{(v)}\right]^{2}}
\end{array}\right],
$$

where $\omega^{(i)} \in(0, \infty)$ for $i=g, v$, and $0<d_{v}^{(g)}<1 .{ }^{5}$ Note that the FIGARCH model is not covariance stationary. The question whether it is strictly stationary or not is still open at present (see Conrad and Haag, 2006). In the FIGARCH model, conditions on the parameters have to be imposed to ensure the non-negativity of the conditional variances (see Conrad and Haag, 2006). ${ }^{6}$

Estimates of the fractional mean parameters are shown in table $2 .{ }^{7}$ Several findings emerge from this table. Number of trades and volatility generated very similar long-memory parameters, 0.47 and 0.43 respectively. The estimated value of $d_{m}^{(v s)}, 0.60$, is greater than the corresponding values for number of trades and volatility. In the mean equation for the volatility the long-memory coefficient $d_{m}^{(g)}$ is robust to the measures of volume used. In other words, the bivariate ARFI models 1 and 2 generated very similar $d_{m}^{(g)}$ 's fractional parameters, 0.47 and $0.43 .^{8}$

Moreover, $d_{v}^{(g)}$ 's govern the long-run dynamics of the conditional heteroscedasticity of volatility. The fractional parameter $d_{v}^{(g)}$ is robust to the measures of volume used. In other words, the two bivariate FIGARCH models generated very similar estimates of $d_{v}^{(g)}: 0.57$ and 0.58 . All four mean long-memory coefficients are robust to the presence of outliers in volatility. When we take into account these outliers the estimated value of $d_{v}^{(g)}$ falls from 0.57 to 0.44 but remains highly significant.

\footnotetext{
${ }^{5}$ Brandt and Jones (2006) use the approximate result that if log returns are conditionally Gaussian with mean 0 and volatility $h_{t}$ then the log range is a noisy linear proxy of log volatility. In this paper we model the GK volatility as an AR-FI-GARCH process.

${ }^{6}$ Baillie and Morana (2007) introduce a new long-memory volatility process, denoted by Adaptive FIGARCH which is designed to account for both long-memory and structural change in the conditional variance process. One could provide an enrichment of the bivariate dual long-memory model by allowing the intercepts of the two means and variances to follow a slowly varying function as in Baillie and Morana (2007). This is undoubtedly a challenging yet worthwhile task.

7 Three tests aimed at distinguishing short and long-memory are implemented for the data. The statistical significance of the statistics (not reported) indicates that the data are consistent with the long-memory hypothesis. In addition, we test the hypothesis of long-memory following Robinson's (1995) semiparametric bivariate approach (see, also, Karanasos and Kartsaklas, 2008b).

${ }^{8}$ It is worth mentioning that there is a possibility that, at least, part of the long-memory may be caused by the presence of neglected breaks in the series (see, for example, Granger and Hyung, 2004). Therefore, the fractional integration parameters are estimated taking into account the 'presence of breaks' by including the dummy variables for introduction of futures and option trading. Interestingly enough, the long-memory character of the series remain strongly evident.
} 
Table 2. Long memory in volatility and levels

Panel A. Garman-Klass volatility

$\begin{array}{lll}\text { Long memory \& ccc } \quad d_{m}^{(i)} & d_{v}^{(i)} & \rho\end{array}$

Model 1 (Value of shares traded, vs)

Eq. 1 Volatility $y_{t}^{(g)} \quad 0.47(0.10)^{* * *} \quad 0.57(0.08)^{* * *} \quad$ -

$\begin{array}{llll}\text { Eq. } 2 \text { Volume } y_{t}^{(v s)} & 0.60(0.04)^{* * *} \quad- & 0.28(0.03)^{* * *}\end{array}$

Model 2 (Number of trades, $n$ )

Eq. 1 Volatility $y_{t}^{(g)} \quad 0.43(0.09)^{* * *} \quad 0.58(0.09)^{* * *} \quad$ -

Eq. 2 Volume $y_{t}^{(n)} \quad 0.47(0.03)^{* * *} \quad-\quad 0.30(0.03)^{* * *}$

Panel B. Outlier reduced Garman-Klass volatility

Model 1 (Value of shares traded)

Long memory \& ccc $\quad d_{m}^{(i)} \quad d_{v}^{(i)} \quad \rho$

Eq. 1 Volatility $y_{t}^{(g)} \quad 0.42(0.04)^{* * *} \quad 0.44(0.08)^{* * *} \quad$ -

Eq. 2 Volume $y_{t}^{(v s)} \quad 0.60(0.04)^{* * *} \quad-\quad 0.30(0.03)^{* * *}$

Model 2 (Number of trades)

$\begin{array}{llll}\text { Eq. } 1 \text { Volatility } y_{t}^{(g)} & 0.39(0.04)^{* * *} & 0.44(0.08)^{* * *} & - \\ \text { Eq. 2 Volume } y_{t}^{(n)} & 0.48(0.03)^{* * *} & - & 0.31(0.03)^{* * *}\end{array}$

Notes: The table reports parameter estimates of the long-memory

and the ccc coefficients. $d_{m}^{(i)}, d_{v}^{(i)}, i=v, g$, and $\rho$ are defined in

equation (1).*** denote significance at the 0.05 level

respectively. The numbers in parentheses are standard errors.

The variances of the two measures of volume generated very similar conditional correlations with the variance of volatility: $0.28,0.30$. Finally, the estimated values of the $\mathrm{ARCH}$ coefficients in the conditional variances of the value of shares and number of trades are 0.12 and 0.13 respectively. Note that in all cases the necessary and sufficient conditions for the non-negativitiy of the conditional variances are satisfied (see Conrad and Haag, 2006). 


\subsection{The relationship between volume and volatility}

We employ the bivariate ccc AR-FI-GARCH model with lagged values of one variable included in the mean equation of the other variable to test for bidirectional causality. The estimated coefficients $\phi_{s}^{(i j)}$, $\left(\phi_{3}^{(g v)}, \phi_{1}^{(v g)}\right)$ respectively defined in equation (1), which capture the possible feedback between the two variables, are shown in the first column of table 3 . All four $\phi_{3}^{(g v)}$ estimates are significant and negative. Note that both volume series have a similar impact on GK volatility $(-0.013,-0.014)$. This result is in line with the theoretical underpinnings predicting that, all else being equal, a marketplace with a larger capacity to absorb demands for liquidity will be less volatile than one with a smaller capacity. On the other hand, in all cases the $\phi_{1}^{(v g)}$ coefficients are insignificant, indicating that lagged volatility is not associated with current volume. Therefore in the period before the introduction of futures trading volatility affects volume negatively whereas there is no effect in the opposite direction. 
Table 3. Mean Equation: Cross effects

Panel A. Garman-Klass volatility

Cross Effects

$\phi_{s}^{(i j)} \quad \phi_{s}^{(i j, f)} \phi_{s}^{(i j, o)}$

Model 1 (Value of shares traded, vs)

Eq. 1 Volatility $y_{t}^{(g)}(i=g, j=v s, s=3) \quad-0.013(0.006)^{* * *} \quad 0.003(0.008) \quad 0.009(0.006)^{*}$

Eq. 2 Volume $y_{t}^{(v s)}(i=v s, j=g, s=1) \quad-0.110(0.259) \quad-0.161(0.507) \quad 0.117(0.461)$

Model 2 (Number of Trades, $n$ )

Eq. 1 Volatility $y_{t}^{(g)}(i=g, j=n, s=3) \quad-0.014(0.008)^{* * *} \quad 0.006(0.010) \quad 0.008(0.007)$

Eq. 2 Volume $y_{t}^{(n)}(i=n, j=g, s=1) \quad 0.120(0.177) \quad-0.006(0.330) \quad-0.255(0.317)$

Panel B. Outlier reduced Garman-Klass volatility

Cross Effects

$$
\phi_{s}^{(i j)} \quad \phi_{s}^{(i j, f)} \quad \phi_{s}^{(i j, o)}
$$

Model 1 (Value of shares traded)

Eq. 1 Volatility $y_{t}^{(g)}$

Eq. 2 Volume $y_{t}^{(v s)}$

Model 2 (Number of Trades)

Eq. 1 Volatility $y_{t}^{(g)}$

Eq. 2 Volume $y_{t}^{(n)}$

$$
\begin{array}{ccc}
-0.008(0.004)^{* *} & -0.001(0.006) & 0.009(0.005)^{* *} \\
-0.065(0.302) & -0.340(0.586) & -0.558(0.694)
\end{array}
$$

Notes: The table reports parameter estimates of the cross effects. $\phi_{s}^{(i j)}, \phi_{s}^{(i j, f)}$, and $\phi_{s}^{(i j, o)}, i j=v g, g v$, defined in equation (1). $s$ is the order of the lag. $*, * *, * * *$ denote significance

at the $0.15,0.10$, and 0.05 level respectively. The numbers in parentheses are standard errors.

Estimated values of the dummy coefficients for the cross effects are presented in the last two columns of table 3. Recall that the relationship between the two variables in the second period is captured by the sum of the coefficients in the first two columns while $\left(\phi_{s}^{(i j)}+\phi_{s}^{(i j, f)}+\phi_{s}^{(i j, o)}\right)$ captures the link commencing with the introduction of options contracts. All $\phi_{s}^{(i j, f)}\left(\phi_{3}^{(g v, f)}, \phi_{1}^{(v g, f)}\right)$ estimates are insignificant. Thus it appears that the introduction of futures trading does not influence the volume-volatility link.

As far as the introduction of options contracts is concerned, there seems to be a change in the influence of the value of shares traded on volatility. In particular, when $v=v s$, the estimated $\phi_{3}^{(g v, o)}$ coefficient 
is positive and significant (0.009). However, it is less than the estimate of $\left|\phi_{3}^{(g v)}\right|(0.013)$. Thus in the period which starts with the introduction of options trading the impact of the value of shares traded on volatility is still negative but much smaller in size $\phi_{3}^{(g v)}+\phi_{3}^{(g v, o)}=-0.004, v=v s$. As can be seen from Panels A and B of table 3 the volume-volatility link is, in general, robust to the presence of outliers in volatility.

Overall, in all cases volume is independent of changes in volatility. In other words, causality runs only from volume-either value of shares traded or number of trades-to volatility (see table 3 ). In particular, in all three periods the number of trades affects volatility negatively with the introduction of derivatives trading leaving the sign and the magnitude of this relationship unaltered. In other words, the introduction of the two financial instruments is not affecting the information role of the number of trades in terms of predicting future volatility. One possible explanation is that the use of number of trades as a proxy for volume does not reflect the fact that traders might take larger spot positions after the introduction of derivatives trading due to increased risk sharing opportunities.

Similarly, in all three periods the value of shares traded has a negative effect on volatility. This result is consistent with the views that (i) the activity of informed traders is often inversely related to volatility, and (ii) a marketplace with a larger population of liquidity providers will be less volatile than one with a smaller population. It is also in line with the results in Karanasos and Kartsaklas (2008a), who find that, in Korea, the causal negative effect from total volume to volatility reflects the causal relation between foreign volume and volatility before the financial crisis. It is noteworthy that in the period from the opening of the options market until the end of the sample its impact on volatility, although still significantly negative, is much smaller in size. Hence, introduction of options trading may have weakened the impact volume has on volatility through the information route. Table 4 below gives an overview of the volume-volatility link over the three different periods considered. 
Table 4. The Volume-Volatility link

\begin{tabular}{lccl}
\hline Period: & Period 1 & Period 2 & Period 3 \\
Panel A. The effect of Volume on Volatility & \\
Value of shares traded & negative & negative & negative (smaller) \\
Number of trades & negative & negative & negative \\
\hline Panel B. The impact of Volatility on Volume & \\
Value of shares traded & insignificant & insignificant & insignificant \\
Number of trades & insignificant & insignificant & insignificant \\
\hline
\end{tabular}

\subsection{Expiration and other effects of derivatives trading}

In section 4 we explored the effect of the expiration of derivatives contracts on some aspects of the underlying cash market using simple parametric and non-parametric tests. Next, we pursue a more careful examination of the likely impact of derivatives contracts expiration on trading volume and rangebased volatility. When the value of shares traded is used as a measure of volume the model indicates that there is a significant expiration day effect. In both equations of model 1 the estimates of $\mu^{(i, e)}$, $i=v s, g$, are statistically significant, albeit with opposite signs (see table 5). The value of shares traded on expiration days is higher, on average, than their value on non-expiration days, while volatility is lower on expiration days than on other days. In sharp contrast there is no evidence that the expiration of derivatives contract affects the number of trades. That is, the estimated value of $\mu^{(n, e)}$ is insignificant.

It is easily seen that the estimated expiration day impact on volume is similar to the cruder comparison of expiration day and non-expiration day volumes earlier in this paper. The estimated effect of expiration of derivatives contracts on GK volatility, on the other hand, is significantly different from those reported in Section 4. Our non-parametric test of the equality of means of the distributions of expiration day and non-expiration day volatility had indicated that there is no effect. By contrast, our estimates from the bivariate dual long-memory model suggest that the impact of derivatives expiration on volatility is negative. This contrast, however, is consistent with the results in Bhaumik and Bose (2008), who found that while mean value of GK volatility on expiration and non-expiration days are not significant, derivatives contract expiration affects GARCH volatility negatively. They concluded that one should, 
therefore, be wary about drawing conclusions from results of simple parametric or non-parametric tests, and that it would be prudent to verify the results using models like (variations of) GARCH that capture the actual data generating process.

Next, we investigate whether the opening of the futures and options markets affects spot price volatility and trading volume. Recall that the coefficients $\mu^{(i, f)}, \mu^{(i, o)}, i=g, v$, capture the effects of derivatives trading on spot volatility and volume. The estimate $\mu^{(g, f)}$ is negative and significant, indicating that the introduction of futures trading leads to a decrease in spot volatility. One possible explanation is provided by Stein (1987). Once futures are introduced increases in the number of uniformed traders are beneficial even though such increases lower the average informedness of market participants. The latter is mitigated by the increase in risk sharing and the fact that spot traders tend to offset any mistakes the secondary traders make. The above result also supports the Hong (2000) theory that stock volatility is negatively related to futures trading activity. The reason being that when a futures market is opened investors are able to better hedge their nonmarketed risks and therefore are willing to absorb more of the nonmarketed risk shocks in their spot holdings. It is also in line with the findings in Bessembinder and Seguin (1992). On the other hand, options trading has no significant impact on spot volatility since the coefficient $\mu^{(g, o)}$ is insignificant in all cases. This result is consistent with that of Bollen (1998), who did not find any impact of options trading on the volatility of the underlying stock. 
Table 5. Mean Equation: Dummy effects for constants

Panel A. Garman-Klass volatility

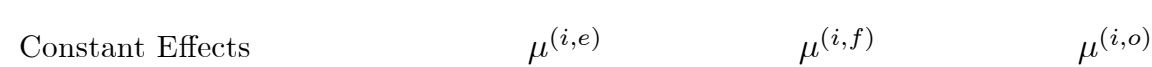

Model 1 (Value of shares traded, vs)

Eq. 1 Volatility $y_{t}^{(g)}, i=g \quad-0.003(0.002)^{* *} \quad-0.12(0.009)^{*} \quad-0.003(0.005)$

Eq. 2 Volume $y_{t}^{(v s)}, i=v s \quad 0.108(0.022)^{* * *} \quad-0.030(0.154) \quad-0.746(0.344)^{* * *}$

Model 2 (Number of trades, $n$ )

Eq. 1 Volatility $y_{t}^{(g)}, i=g \quad-0.003(0.002)^{* *} \quad-0.014(0.009)^{*} \quad-0.003(0.002)$

Eq. 2 Volume $y_{t}^{(n)}, i=n \quad 0.004(0.015) \quad-0.073(0.106) \quad-0.503(0.295)^{* *}$

Panel B. Outlier reduced Garman-Klass volatility

Model 1 (Values of shares traded)

Constant Effects

$\mu^{(i, e)}$

$\mu^{(i, f)}$

$\mu^{(i, o)}$

Eq. 1 Volatility $y_{t}^{(g)}$

$-0.003(0.002)^{* *}-0.013(0.007)^{* * *}$

$-0.004(0.005)$

Eq. 2 Volume $y_{t}^{(v s)}$

$0.105(0.022)^{* * *}$

$-0.033(0.154)$

$-0.743(0.342)^{* * *}$

Model 2 (Number of trades)

\begin{tabular}{lccc} 
Eq. 1 Volatility $y_{t}^{(g)}$ & $-0.003(0.002)^{* *}$ & $-0.014(0.006)^{* * *}$ & $-0.004(0.005)$ \\
Eq. 2 Volume $y_{t}^{(n)}$ & $0.001(0.016)$ & $0.065(0.105)$ & $-0.505(0.299)^{* *}$ \\
\hline
\end{tabular}

Notes: The table reports parameter estimates of the constant dummy effects.

$\mu^{(i, e)}, \mu^{(i, f)}$ and $\mu^{(i, o)}, i=v, g$, are defined in equation (1).

$*, * *, * * *$ denote significance at the $0.15,0.10,0.05$ level respectively.

The numbers in parentheses are standard errors.

In sharp contrast, since the estimates $\mu^{(v, f)}(v=v s, n)$ are insignificant, it appears that the average levels of value of shares traded and of number of trades remain the same before and after the introduction of futures trading. However, the negative and significant estimated values of $\mu^{(v, o)}$ indicate that on average the value of shares traded and the number of trades decrease after the introduction of option contracts. This result is in line with the theoretical argument in Kumar et al. (1995). They argue that the migration of some speculators to options markets on the listing of options is accompanied by a decrease in trading 
volume in the underlying security.

These results are quite robust across models 1 and 2 and across panels $\mathrm{A}$ and B. In other words, in all cases the results are not qualitatively altered by changes in the measures of volume and they are not sensitive to the presence of outliers in volatility.

\section{Discussion}

In this section we discuss our results within the context of the Indian market. The evidence of a negative volume-volatility link in India is possibly an outcome of increasing liquidity. According to Kawaller et al. (2001), all else being equal, a marketplace with a larger capacity to absorb demand for liquidity will be less volatile than one with a smaller capacity. By 1996-97, i.e., within two years of initiation of trading at the NSE, more than 100,000 trades were being executed per day, leading to an exchange of more than 13 billion shares over the course of the year. The corresponding figures at the turn of the century, in 1999-2000, were about 400,000 - a four-fold increase - and 24 billion. These are fairly large numbers given that fewer than 1000 companies were listed at the exchange during this period.

In order to explain our results about the impact of derivatives trading on volume, volatility, and their relationship, we have to revisit some aspects of the equity market in India. Kumar, et al. (1995) have argued that the introduction of options contracts leads to a migration of speculators from the cash market to the options market. It is entirely possible that in India the introduction of trading in equity derivatives led to a migration of speculators from the cash market to the futures and options markets. As we mentioned earlier in the paper, week-long trading cycles enabled speculators to simulate futures trading within the cash market, a practice that ended with the introduction of rolling settlement. At the same time, the basic mechanism of badla trading was to take a position on a stock, not take delivery at the end of the trading cycle, and roll it over to the following trading cycle. While badla traders had to pay interest to the financiers who provided the mezzanine finance to facilitate this roll over, there was no daily mark to market and margin call, unlike in a futures market. Hence, badla trading worked quite similarly to options markets, with the interest paid to the financiers acting as the price for the implicit call option on the underlying shares. In other words, traders who took speculative positions and reversed 
them within trading cycles, and/or made use of badla trading as the vehicle for speculation, were more likely to use the futures and options markets for undertaking speculation than the cash market, in the aftermath of introduction of derivatives trading.

These speculators migrating to the derivatives market were also likely to have been market insiders who trade on the basis of a fair amount of public as well as privately held information. There is some evidence to support this hypothesis in the research of Raju and Karande (2003), who find that once derivatives markets were introduced price discovery was more likely to have taken place in the futures market than in the cash market. Further, the Economic Survey for 2005-06, published by the Government of India, as of 2005, states that the number of accounts held by retail investors at the two depositories in the country, NSDL and CSDL, stood at 8.5 million, confirming that a large proportion of cash market traders were unsophisticated. Support for the preponderance of retail investors in the cash market in the post-derivatives regime is also provided by table 6 , which compares the percentage changes in the number of trades and those in the number of shares traded in the cash market since 2001-02. The number of trades kept increasing at a rapid pace, but since 2004-05 the number of stocks changing hands has increased at a much slower rate. In other words, since the introduction of derivatives trading in general, and options trading in particular, an increasing proportion of the trades in the cash market possibly involved retail investors.

Table 6. Number of trades and shares traded (\% Changes).

\begin{tabular}{lllll}
\hline & & \multicolumn{3}{c}{ Traded } \\
Year & No. of Trades & \% change & Quantity & \% change \\
& (Million) & & (Billion) & \\
& & & 27.84 & -15.50 \\
$2001-2002$ & 175.30 & 4.60 & 36.41 & 30.80 \\
$2002-2003$ & 239.80 & 36.80 & 71.33 & 95.90 \\
$2003-2004$ & 378.00 & 57.60 & 79.77 & 11.80 \\
$2004-2005$ & 451.00 & 19.30 & 84.45 & 5.90 \\
$2005-2006$ & 608.80 & 35.00 & 85.55 & 1.30 \\
\hline $2006-2007$ & 784.60 & 28.90 & & \\
\hline
\end{tabular}


We now attempt to explain the result that the introduction of futures trading reduced spot volatility. If sophisticated traders in the futures market facilitate rapid price discovery, thereby providing the relatively unsophisticated traders in the cash market focal points with respect to prices, spot volatility is likely to decrease. This is consistent with the argument by Stein (1987), namely, that when the addition of speculators just raises the number of perfectly informed participants in the market and, hence, has no informational effect at all, then the opening of a futures market is stabilizing and welfare improving.

Next, we explain the two observed impacts of the listing of options. The first one is a decline in the volume of trading in the cash market. As highlighted above, in the Indian context, in keeping with the arguments of Kumar, et al. (1995), the introduction of derivatives trading may have led to a migration of some traders from the cash to the derivatives markets. There is some evidence to suggest that much of this migration may have been to the options market, thereby reducing trading volume in the cash market. Between 2004-05 and 2006-07, the number of options contracts traded at the NSE quadrupled from 12.94 million to 50.49 million.

We also have to explain the observation that in the period from the introduction of options contracts until the end of the sample the impact of the value of shares traded on volatility, although still significantly negative, is much smaller in size. Note that while sophisticated traders with private information may have migrated to the derivatives markets, those migrating to the futures market were almost certainly disseminating information in the cash market by facilitating price discovery. By contrast, private information of the sophisticated traders in the options markets may not have reached the relatively less sophisticated traders in the cash market, given the inefficiency in the Indian stock market (Sarkar and Mukhopadhyay, 2005). In any event, the retail investors, who are presumably counterparties to a very significant proportion of the trades, are possibly not sophisticated enough to interpret information signals given out by trades involving options contracts. Hence, the advent of options trading may have weakened the impact volume has on volatility through the information route.

Finally, we provide a plausible explanation for a result that the literature suggests should have been observed, but one that we did not observe, namely, a negative impact of introduction of options trading on spot volatility. Our result is consistent with that of Bollen (1998), who did not find any such impact in 
the US. But it is at odds with Kumar et al. $(1995,1998)$, who point out that options reduce the volatility of the underlying stock because (i) they improve the efficiency of incomplete asset markets by expanding the opportunity set facing investors, (ii) speculative traders migrate from the underlying market to the options market since they view options as superior speculative vehicles. As a result the amount of noise trading in the spot market is reduced. They also argue that liquidity in the underlying market improves because informed traders, since they view options as superior investment vehicles, shift to the options market. Finally, they argue that options may improve the efficiency of the underlying market by increasing the level of public information in the market. We have already noted the inefficiency in the Indian market. Further, with speculators with superior information migrating to the options (and generally speaking derivatives) market, and with the consequent preponderance of retail investors in the cash market, noise trading in the latter market may have actually increased. Hence, many of the possible ways in which the introduction of options contracts might have increased the quality of the underlying cash markets were unlikely to have worked out in the Indian context.

\section{Conclusions}

This paper has investigated the issue of temporal ordering of the range-based volatility and trading volume in the NSE, the largest cash and derivatives exchange in India, for the period 1995-2007. We examined the dynamics of the two variables and their respective uncertainties using a bivariate dual long-memory model. We also distinguished volume traded before and after the introduction of futures and options trading and we derived several important conclusions.

First, in all three periods the impact of number of trades on volatility is negative. Similarly, the value of shares traded has a negative effect on volatility as well. This result is in line with a version of the MDH model in which the higher the intensity of liquidity trading the lower the price volatility. However, in the period from the opening of options markets until the end of the sample the impact, although still significantly negative, is much smaller in size. Hence, introduction of options trading may have weakened the impact volume has on volatility through the information route. In sharp contrast, volume is independent of changes in volatility. 
Our second conclusion is that the introduction of futures trading leads to a decrease in spot volatility. This finding offers support to the theoretical arguments of Stein (1987) and Hong (2000). However, option listings have a negative but insignificant effect on spot volatility. It is therefore evident that the possible ways in which the introduction of options might have increased the quality of the underlying cash markets were unlikely to have worked out in the Indian context. Thirdly, volume decrease after the introduction of option contracts, offering support to the view that the migration of some speculators to options markets on the listing of options, is accompanied by a decrease in trading volume in the underlying security.

Finally, we also indicate that expirations of equity based derivatives have significant impact on the value of shares traded on expiration days and on the range-based volatility. Therefore, our results reinforce the conclusions of Bhaumik and Bose (2008) that it might be useful to undertake an analysis of expiration day effects (and other events) using an approach that models the underlying data generating process, rather than one which depends on comparison of means and medians alone.

\section{References}

[1] Alkeback, P., and Hagelin, N., 2004. Expiration day effects of index futures and options: evidence from a market with a long settlement period. Applied Financial Economics, 14, 6, 385-396.

[2] Andersen, T., 1996. Return volatility and trading volume: an information flow interpretation of stochastic volatility. Journal of Finance, 1, 169-204.

[3] Bae, S. C., Kwon, T. H., Park, J. W., 2004. Futures trading, spot market volatility, and market efficiency: the case of the Korean index futures markets. Journal of Futures Markets, 24, 1195-1228.

[4] Bai, J., and Perron, P., 2003. Computation and analysis of multiple structural change models. Journal of Applied Econometrics, 18, 1-22.

[5] Baillie, R., Bollerslev, T., and Mikkelsen, H., 1996. Fractionally integrated generalized autoregressive conditional heteroskedasticity. Journal of Econometrics, 74, 3-30.

[6] Baillie, R., and Morana, C., 2007. Modeling long memory and structural breaks in conditional variances: an adaptive FIGARCH approach. ICER, Working Paper No. 11/2007. 
[7] Bandivadekar, S., and Ghosh, S., 2003. Derivatives and volatility in the Indian stock markets. Reserve Bank of India Occasional Papers, 24(3), 187-201.

[8] Bessembinder H., Seguin, P., 1992. Futures-trading activity and stock price volatility. Journal of Finance, 47, 2015-2034.

[9] Bhaumik, S. K., and Bose, S., 2008. Impact of derivatives trading on emerging stock markets: Some evidence from India. Comparative Economic Studies, forthcoming.

[10] Board, J., Sandmann, G., Sutcliffe, C., 2001. The effect of futures market volume on spot market volatility. Journal of Business, Finance and Accounting, 28, 799-819.

[11] Bollen, N. P. B., 1998. A note on the impact of options on stock volatility. Journal of Banking and Finance, 22, 1181-1190.

[12] Bollen, N.P.B., and Whaley, R.E., 1999. Do expirations of Hang Seng index derivatives affect stock market volatility? Pacific Basin Finance Journal, 7, 453-470.

[13] Bollerslev, T., and Jubinski, D., 1999. Equity trading volume and volatility: latent information arrivals and common long-run dependencies. Journal of Business \& Economic Statistics, 1, 9-21.

[14] Brandt, M. W., and Jones, C. S., 2006. Volatility forecasting with range-based EGARCH models. Journal of Business \& Economic Statistics, 24, 470-486.

[15] Brown-Hruska, S., Kuserk, G., 1995. Volatility, volume and the notion of balance in the S\&P 500 cash and futures markets. Journal of Futures Markets, 15, 677-689.

[16] Carnero, M. A., Peña, D., and Ruiz, E., 2007. Effects of outliers on the identification and estimation of GARCH models. Journal of Time Series Analysis, 28, 471-497.

[17] Chen, Z., and Daigler, R., 2004. Linear and nonlinear interaction among futures volatility, institutional traders, and the general public. Mimeo. Department of Finance, Florida International University.

[18] Chen, Z., Daigler, R., and Parhizgari, A., 2006. Persistence of volatility in future markets. Journal of Futures Markets, 26, 571-594. 
[19] Chow, Y. F., Yung. H. H. M., and Zhang, H., 2003. Expiration day effects: The case of Hong Kong. The Journal of Futures Markets, 1, 67-86.

[20] Chou, R. Y., 2005. Forecasting financial volatilities with extreme values: the conditional autoregressive range (CARR) model. Journal of Money, Credit, and Banking, 37, 561-582.

[21] Conrad, C., and Haag, B., 2006. Inequality constraints in the FIGARCH model. Journal of Financial Econometrics, 3, 413-449.

[22] Corredor, P., Lechon, P., and Santamaria, R., 2001. Option expiring effects in small markets: The Spanish stock exchange. The Journal of Futures Markets, 10, 905-928.

[23] Daigler, R., and Wiley, M., 1999. The impact of trader type on the futures volatility-volume relation. Journal of Finance, 6, 2297-2316.

[24] Damodaran, A., Subrahmanayan, M., 1992. The effects of deivative securities on the markets for the underlying assets in the United States: a survey. Financial Markets, Institutions and Instruments, $2,1-21$.

[25] Davidson, J., 2008. Time Series Modelling 4.26. http://www.timeseriesmodelling.com.

[26] Dennis, S. A., Sim, A. B., 1999. Share price volatility with the introduction of individual share futures on the Sydney Futures Exchange. International Review of Financial Analysis, 8, 153-163.

[27] Easley, D., Hvidkjaer, S., and O' Hara, M., 2002. Is information risk a determinant of asset returns? Journal of Finance, 57, 2185-2221.

[28] Easley, D., Kiefer, N., O' Hara, M., and Paperman J., 1996. Liquidity, information, and infrequently traded stocks. Journal of Finance, 51, 1405-1436.

[29] Edwards, F. R., 1988. Does futures trading increase stock market volatility?. Financial Analysts Journal, Jan.-Feb. 63-69.

[30] Gammill, J. F., Marsh, T., 1988. Trading activity and price behavior in the stock and stock index futures markets in october 1987. Journal of Economic Perspectives, 2, 25-44. 
[31] Gammill, J. F., Perold, A. F., 1989. The changing character of stock market liquidity. Journal of Portfolio Management, Spring, 13-18.

[32] Garman, M., and Klass, M., 1980. On the estimation of security price volatilities from historical data. Journal of Business, 1, 67-78.

[33] Ghysels, E., Seon, J., 2005. The Asian financial crisis: the role of derivative securities trading and foreign investors in Korea. Journal of Intenational Money and Finance, 24, 607-630.

[34] Granger, C., and Hyung, N., 2004. Occasional structural breaks and long memory with an application to the S\&P 500 absolute stock returns. Journal of Empirical Finance, 11, 399-421.

[35] Gulen, H., and Mayhew, S., 2000. Stock index futures trading and volatility in international equity markets. Journal of Futures Markets, 7, 661-685.

[36] Gupta, R., 1995. Badla trading: A primer and a proposal. Mimeo. Indian Institute of Management, Ahmedabad.

[37] Gupta, R., 1997. Badla trading: A reappraisal. Mimeo. Indian Institute of Management, Ahmedabad.

[38] Hong, H., 2000. A model of returns and trading in futures markets. Journal of Finance, 55, 959-988.

[39] Karanasos, M., and Kartsaklas, A., 2008a. Dual long-memory, structural breaks and the link between turnover and the range-based volatility Mimeo. Economics and Finance, Brunel University.

[40] Karanasos, M., and Kartsaklas, A., 2008b. Common long-run dependencies in stock volatility and trading volume: the Korean experience. Mineo. Economics and Finance, Brunel University.

[41] Kawaller, I., Koch, P., and Peterson, J., 2001. Volume and volatility surrounding quarterly redesignation of the lead S\&P 500 futures contract. Journal of Future Markets, 12, 1119-1149.

[42] Kim, J., Kartsaklas, A., and Karanasos, M., 2005. The volume-volatility relationship and the opening of the Korean stock market to foreign investors after the financial turmoil in 1997. Asia-Pacific Financial Markets, 12, 245-271. 
[43] Kumar, R., Sarin, A, and Shastri, K., 1995. The impact of index options on the underlying stocks: The evidence from the listing of Nikkei stock average options. Pacific-Basin Finance Journal, 3, 303-317.

[44] Kumar, R., Sarin, A, and Shastri, K., 1998. The impact of otpions trading on the market quality of the underlying security: an empirical analysis. Journal of Finance, LIII, 717-732.

[45] Lavielle, M., and Moulines, E., 2000. Least-squares estimation of an unknown number of shifts in a time series. Journal of Time Series Analysis, 21, 33-59.

[46] Li, J., and Wu, C., 2006. Daily return volatility, bid-ask spreads, and information flow: analyzing the information content of volume. Journal of Business, 79, 2697-2740.

[47] Mayhew, S., 2000. The impact of derivatives on cash market: What have we learnt? Mimeo. University of Georgia at Athens.

[48] Megginson, W. L., and Weiss, K. A., 1991. Venture capitalist certification in initial public offerings. Journal of Finance, Papers and Proceedings, 3, 879-903.

[49] Raju, M.T., and Karande, K., 2003. Price discovery and volatility on NSE futures market. Working paper series no. 7, Securities and Exchange Board of India.

[50] Robinson, P., 1995. Log-periodogram regression of time series with long-range dependence. Annals of Statistics, 23, 1048-1072.

[51] Sarkar, N. and Mukhopadhyay, D., 2005. Testing predictability and nonlinear dependence in the Indian stock market. Emerging Market Finance and Trade, 41, 7-44.

[52] Stein, J. C., (1987). Informational externalities and welfare-reducing speculation. Journal of Political Economy, 95, 1123-1145.

[53] Stoll, H.R., and Whaley, R.E., 1997. Expiration day effects of the All Ordinaries Share Price index futures: Empirical evidence and alternative settlement procedures. Australian Journal of Management, 22, 139-174. 
[54] Subrahmanyan, A., 1991. A theory of trading in stock index futures. The Review of Financial Studies, $4,17-51$.

[55] Tsay, W., and Chung, C., 2000. The spurious regression of fractionally integrated processes. Journal of Econometrics, 96, 155-182.

[56] Vilasuso, J., 2001. Causality tests and conditional heteroscedasticity: Monte Carlo evidence. Journal of Econometrics, 1, 25-35.

[57] Vipul, 2005. Futures and options expiration-day effects: The Indian evidence. The Journal of Futures Markets, 11, 1045-1065.

[58] Vipul, 2006. Impact of the introduction of derivatives on underlying volatility: Evidence from India. Applied Financial Economics, 16(9), 687-697.

[59] Wang, C., 2002. The effect of net positions by type of trader on volatility in foreign currency futures markets. Journal of Future Markets, 5, 427-450.

[60] Wang, J., 2007. Foreign equity trading and emerging market volatility: evidence from Indonesia and Thailand. Journal of Development Economics, 84, 798-811. 


\section{DAVIDSON INSTITUTE WORKING PAPER SERIES - Most Recent Papers}

The entire Working Paper Series may be downloaded free of charge at: www.wdi.umich.edu

CURRENT AS OF 10/2/08

\begin{tabular}{|c|c|c|}
\hline Publication & Authors & Date \\
\hline $\begin{array}{l}\text { No. 935: Derivatives trading and the volume-volatility link in the Indian } \\
\text { Stock Market }\end{array}$ & $\begin{array}{l}\text { S. Bhaumiky, M. Karanasosy and } \\
\text { A. Kartsaklas }\end{array}$ & April 2008 \\
\hline $\begin{array}{l}\text { No. 934: Yuan Real Exchange Rate Undervaluation, 1997-2006. How } \\
\text { Much, How Often? Not Much, Not Often }\end{array}$ & $\begin{array}{l}\text { Jeff Chen, Wende Deng \& David } \\
\text { Kemme }\end{array}$ & Aug 2008 \\
\hline $\begin{array}{l}\text { No. 933: How Important Are Foreign Shocks in Small Open Economy? } \\
\text { The Case of Slovakia }\end{array}$ & $\begin{array}{l}\text { Roman Horváth and Marek } \\
\text { Rusnák }\end{array}$ & Sept 2008 \\
\hline $\begin{array}{l}\text { No. 932: Estimating Poverty for Indigenous Groups in Chile } \\
\text { by Matching Census and Survey Data }\end{array}$ & $\begin{array}{l}\text { Claudio A. Agostini, Philip H. } \\
\text { Brown, and Andrei Roman }\end{array}$ & Aug 2008 \\
\hline $\begin{array}{l}\text { No. 931: Is There Electoral Cycles In Globalization Process? Evidence } \\
\text { From } 78 \text { Democratic Countries, } 1975 \text { - } 2006\end{array}$ & Krishna Chaitanya Vadlamannati & Sept 2008 \\
\hline No. 930: Lobbying, Corruption \& Other Banes & $\begin{array}{l}\text { Nauro Campos \& Francesco } \\
\text { Giovannoni }\end{array}$ & Sept 2008 \\
\hline $\begin{array}{l}\text { No. 929: Do Elections Slow Down Economic Globalization Process In } \\
\text { India? It's Politics Stupid! }\end{array}$ & Krishna C Vadlamannati & Aug 2008 \\
\hline $\begin{array}{l}\text { No. 928: Impact Of Institutional Quality On Human Rights Abuses } \\
\text { In Transition Economies }\end{array}$ & $\begin{array}{l}\text { Krishna C Vadlamannati \& Artur } \\
\text { Tamazian }\end{array}$ & July 2008 \\
\hline $\begin{array}{l}\text { No. 927: Do Choice \& Speed Of Reforms Matter For } \\
\text { Human Rights During Transition? }\end{array}$ & Krishna Chaitanya Vadlamannati & July 2008 \\
\hline $\begin{array}{l}\text { No. 926: Socioeconomic, Institutional \& Political Determinants Of } \\
\text { Human Rights Abuses: A Subnational Study Of India, } 1993-2002\end{array}$ & Krishna Chaitanya Vadlamannati & July 2008 \\
\hline $\begin{array}{l}\text { No. 925: Does the Entry Mode of Foreign Banks Matter for Bank } \\
\text { Efficiency? Evidence from the Czech Republic, Hungary, and } \\
\text { Poland }\end{array}$ & $\begin{array}{l}\text { Ngoc-Anh Vo Thi \& Dev } \\
\text { Vencappa }\end{array}$ & July 2008 \\
\hline No. 924: Impact Of Economic Reforms On Poverty - Indian Experience & Krishna Chaitanya Vadlamannati & July 2008 \\
\hline $\begin{array}{l}\text { No. 923: India \& South Asia - Indian Economic Reforms \& Direct } \\
\text { Foreign Investments: How Much Difference Do They Make To } \\
\text { Neighbors? }\end{array}$ & Krishna Chaitanya Vadlamannati & July 2008 \\
\hline $\begin{array}{l}\text { No. 922: The Effects of Monetary Policy in the Czech Republic: } \\
\text { An Empirical Study }\end{array}$ & $\begin{array}{l}\text { Magdalena Morgese Borys and } \\
\text { Roman Horváth }\end{array}$ & May 2008 \\
\hline $\begin{array}{l}\text { No. 921: Goods Market Integration in Russia during the Economic } \\
\text { Upturn }\end{array}$ & Konstantin Gluschenko & May 2008 \\
\hline $\begin{array}{l}\text { No. 920: Labour Market Matching Efficiency In The Czech Republic } \\
\text { Transition }\end{array}$ & Pablo de Pedraza & April 2008 \\
\hline $\begin{array}{l}\text { No. 919: The Emerging Aversion to Inequality: Evidence from Poland } \\
\text { 1992-2005 }\end{array}$ & Irena Grosfeld and Claudia Senik & April 2008 \\
\hline $\begin{array}{l}\text { No. 918: Exploring The Relationship Between Military Spending \& } \\
\text { Income Inequality In South Asia }\end{array}$ & Krishna Chaitanya Vadlamannati & Feb 2008 \\
\hline $\begin{array}{l}\text { No. 917: Productive, Unproductive and Destructive Entrepreneurship: A } \\
\text { Theoretical and Empirical Exploration }\end{array}$ & Arnis Sauka & Mar 2008 \\
\hline $\begin{array}{l}\text { No. 916: MARKET RISK DYNAMICS AND COMPETITIVENESS } \\
\text { AFTER THE EURO: Evidence from EMU Members }\end{array}$ & $\begin{array}{l}\text { Juan Piñeiro Chousa, Artur } \\
\text { Tamazian \& Davit N. Melikyan }\end{array}$ & Feb 2008 \\
\hline No. 915: An Impact Analysis of Microfinance in Bosnia and Herzegovina & $\begin{array}{l}\text { Valentina Hartarska \& Denis } \\
\text { Nadolnyak }\end{array}$ & Dec 2007 \\
\hline $\begin{array}{l}\text { No. 914: Why are Optimistic Entrepreneurs Successful? An Application of } \\
\text { the Regulatory Focus Theory }\end{array}$ & $\begin{array}{l}\text { Ruta Aidis, Tomasz Mickiewicz } \\
\text { \& Arnis Sauka }\end{array}$ & Feb 2008 \\
\hline $\begin{array}{l}\text { No. 913: Measuring Underground (Unobserved, Non-Observed, } \\
\text { Unrecorded) Economies in Transition Countries: Can We Trust GDP? }\end{array}$ & Edgar L. Feige and Ivica Urban & $\begin{array}{c}\text { March } \\
2008\end{array}$ \\
\hline
\end{tabular}

